\title{
A visibilidade dos escondidos
}

| 1 Daniel de Oliveira Costa, ${ }^{2}$ Anamaria Testa Tambellini |

Resumo: Este artigo aborda as manifestaçōes da precarização do trabalho como uma nova e complexa questão social. Procuramos descrever as dimensões humanas implicadas nesse processo de trabalho, traduzindo o nível de exploração de suas relações precárias. Dentre os resultados, destaca-se a relação que esses trabalhadores fizeram de seus sintomas de saúde com seu vínculo de trabalho. A relação precária de trabalho associada à baixa remuneração pode ter manifestações físicas de insônia e medo, refletindo a perda da autoestima. Discutimos a atual reorganização social da produção, em virtude da crise e reestruturação do capitalismo, no último quartel do século $\mathrm{XX}$, que repercutiu no mundo do trabalho, desordenando as relaçôes que conformaram o Estado de Bem-Estar Social e reordenando-as sob a égide da regulação pelo mercado. Concluímos que o trabalhador, frente à sua relação precária de trabalho, tem como preocupação central a ausência de garantias sociais, e suas consequências no longo prazo, quando não mais será útil a esse modelo de exploração da força de trabalho. A pesquisa foi realizada junto a 112 trabalhadores terceirizados por cooperativa, lotados no Serviço de Enfermagem de uma unidade pública de saúde localizada na cidade do Rio de Janeiro, vinculada ao Ministério da Saúde.

> Palavras-chave: Trabalho; precarização; saúde do trabalhador; neoliberalismo; Estado de Bem-Estar Social.

\footnotetext{
1 Economista, mestre em Saúde Coletiva IESC-UFRJ; solon@ iesc.ufrj.br

2 Professora Adjunta no IESCUFRJ; doutora em Ciências da Saúde.
} 
É possível observar, após quase três décadas de reformas estruturais de racionalização do capitalismo, que desenvolvimento econômico não mais significa desenvolvimento social. Os empregos precários já não resultam da ausência de crescimento econômico, mas são inerentes ao próprio modelo de crescimento.

Retomaremos, rapidamente, nossas origens para precisar a questão. O Brasil é resultado da onda de expansão de um sistema mundial que opera por meio de duas forças centrais: a vocação expansiva do capital e a hierarquização geopolítica do sistema entre nações, que determinaram seu deslocamento para além do espaço europeu, na luta pela apropriação de zonas de controle. Nesse sentido, a colonização do território brasileiro é produto direto da expansão do capital comercial e das lutas internas na Europa, por intermédio dos quais, contraditoriamente, é organizada sob bases do trabalho escravo (MORETTI, 2006).

Reside aqui, a nosso ver, um ponto fundamental da formação social brasileira que vai além de uma oposição entre um modo de produção arcaico/escravista e um moderno/capitalista. Para Junior (1999), a alternância contínua entre os dois modos sempre na intenção de progredir dá a medida da nossa aceitação da precariedade originária que se manifestou, inicialmente, na organização pelo capital de uma colônia sobre as bases do trabalho escravo. Portanto, nada mais próximo de uma razão econômica pura do que um espaço social organizado como um empreendimento voltado à acumulação da metrópole. Eis aí, segundo o autor, nossa precariedade de nascença posta nos termos da absoluta centralidade da razão econômica, quando comparada com a vida social. Os desenvolvimentos posteriores foram produzindo alterações substantivas na sociedade e economia brasileiras, mas sempre conectadas às mudanças do sistema mundial. Percorrer os caminhos do trabalho no Brasil significa recuperar essa dimensão histórica de nossa formação social. Se há mais ou menos 50 anos a ênfase na organização social do trabalho estava na proteção do Estado, a partir das duas últimas décadas do século XX, o esforço vem sendo no sentido oposto.

Do ponto de vista das relações de trabalho, a tônica era da formação de uma classe de trabalhadores assalariados que, junto a suas organizaçōes, passavam a estruturar os conflitos de interesses e embates daí resultantes. Constituiu-se uma sociedade salarial, junto à emergência do Pós-Segunda Guerra, cuja correlação de forças sociais e políticas vigentes no período permitiu uma relativa filiação dos 
assalariados à ordem social. Importa ressaltar que tal filiação não representou a supressão dos conflitos de classe e da subordinação do trabalho ao capital. Esse modelo de sociedade salarial baseava-se num compromisso de produção em massa que implicava sucessivos aumentos de produtividade. Os ganhos obtidos pelo aumento da produtividade eram, proporcionalmente, repassados aos salários, a fim de realimentar o consumo de massa e os investimentos dos capitalistas em escala ampliada. Esse modelo se baseava no crescimento contínuo da produção para expandir o emprego formal.

De acordo com Moretti (2006), é importante compreender o processo de formação dessa sociedade salarial associado a um conjunto de proteções e direitos sociais, afiançados pelo Estado, de modo que a inserção dos indivíduos nesta estrutura social passava necessariamente por sua condição salarial. Sua identidade, seu modo de vida, as garantias sociais, o direito ao trabalho, os ganhos salariais, a participação social na produção, o lazer, o nível de consumo e até mesmo seus conflitos estavam vinculados a sua posição nessa estrutura.

Por volta da década de 1970, como observa Prado (2006), esse modelo entra em crise, e nessa crise são repensadas as vantagens e proteções sociais relativas ao trabalho. As manifestaçôes dessa crise podem ser identificadas por dois movimentos importantes: uma reestruturação produtiva, organizacional e geográfica do capital e a dissolução do compromisso relativo às provisões de benefícios sociais por parte do Estado. Embora exista muita controvérsia em torno da natureza dessa crise, dois elementos fundamentais da nova configuração do trabalho no modo capitalista de produção emergem. São eles: o risco e a precariedade sob aspectos variados que vão de novas formas de gestão da força de trabalho até a menor regulamentação das relações de trabalho, passando pela retomada de estratégias de exploração da força de trabalho.

Neste artigo, partimos da hipótese de que o rompimento do modelo de relaçóes capital-trabalho mediado pelo Estado, vigente até a década de 1970, deu origem a uma sociedade na qual explodem várias formas de vínculos laborais. A passagem do "antigo" modelo ao "novo" consiste na mudança de um sistema econômico-social que, embora movido pelos imperativos do capital, produziu a expansão da ocupação assalariada formal e da proteção social, para outro no qual não há quaisquer certezas e as esferas da vida social vão-se mercantilizando.

Ao final da década de 1970, como assinala Tavares (1993), o mercado de trabalho brasileiro já havia alcançado considerável maturidade, e mesmo que já 
não houvesse um repasse dos ganhos de produtividade para os rendimentos dos assalariados, ainda havia forte absorção de mão de obra. As crises da dívida externa e da hiperinflação latente nos anos 80 atingiram duramente os rendimentos do trabalho e aprofundaram a desigualdade de rendas. Mas, apesar das adversidades, continuou havendo absorção de empregos no setor público e um significativo processo de organização sindical. A chamada década perdida não interrompeu a construção de um mercado de trabalho estruturado.

Segundo Teixeira (2000), o mesmo não se pode dizer sobre a turbulenta década de 1990. Nesse período, sob a alegação de serem estimuladoras do crescimento econômico e do emprego, chegam ao Brasil as receitas neoliberais de flexibilização do mercado de trabalho adotadas no Reino Unido e nos EUA, durante o período Thatcher e Reagan. Mesmo com balanços negativos dessas políticas, que já apontavam seu fracasso, seguiu-se o receituário anglo-saxão aqui também, apesar de termos uma situação do trabalho completamente distinta dos altamente organizados mercados de trabalho daqueles países. Lá o resultado foi a ampliação das desigualdades e do desemprego. Aqui, porém, adicionou-se a esses efeitos, uma intensa regressão na qualidade do trabalho.

A partir da análise de dois autores, é possível avaliar essa regressão no mercado de trabalho. Para Standing (1991), a organização do mercado de trabalho capitalista atinge sua maturidade plena nos anos de Pós-Segunda Guerra Mundial na Europa e EUA, e ele identifica alguns de seus elementos básicos, que podemos sintetizar da seguinte maneira: a) segurança no mercado de trabalho - desemprego reduzido e baixo tempo de procura para entrada no, ou mudança de emprego; b) segurança no emprego - emprego formal, de longa duração, com jornada plena e proteção social; c) segurança na renda - remuneração fixa, proteção contra a inflação, incorporação dos ganhos de produtividade, salário mínimo acima da linha de pobreza com seguro-desemprego; d) segurança na contratação - contrato coletivo de trabalho; e) segurança na organização trabalhista - liberdade de organização sindical plena.

A partir desses elementos, Teixeira (2000) avalia objetivamente a regressão do mercado de trabalho nos anos 90 no Brasil. De 1993 a 1997, período em que se observou um crescimento econômico mais robusto, a elasticidade-emprego do PIB caiu mais de $80 \%$ em relação aos medidos nos anos 70 e 80 . O PIB cresceu $22,7 \%$ e a ocupação, apenas $6,0 \%$. Isso exigiria um crescimento do PIB de $8,76 \%$ para absorver um crescimento anual de $2,6 \%$ ao ano da PEA. Como 
o crescimento da produção foi de 4,2\% ao ano, o desemprego subiu. Esta queda do crescimento econômico nos anos 90, média de 2,6\%, metade da média dos cem anos do século XX, foi resultado de uma série de opçôes macroeconômicas restritivas. No Governo Collor, houve a explosão hiperinflacionária, seguida do confisco de ativos financeiros, o que desorganizou profundamente a economia. Durante o colapso político desse governo, adotou-se a blindagem macroeconômica que predominou durante a década, excluídos os primeiros meses de preparação e implantação do Plano Real (jan./94 a mar./95). Juros altos atraíam dólares para a ciranda financeira, deprimindo os investimentos e a atividade produtiva. A estabilização da nova moeda, nos primeiros anos, foi garantida por juros reais elevados e uma âncora cambial que reduziu expressivamente o potencial exportador do país e ampliou drasticamente o déficit de transaçôes correntes. As privatizações foram realizadas para ajudar a fechar o balanço de pagamentos desequilibrado. Essa combinação de juros reais elevados, câmbio sobrevalorizado e privatizaçóes contribuíram para desestruturar o mercado de trabalho brasileiro. O desemprego dobrou na década, os salários reais caíram, os empregos formais desabaram e os informais escalaram. Por isso, os anos 90 são entendidos como regressivos na história recente do mercado de trabalho brasileiro.

Como assinala Prado (2006), após o colapso do câmbio em janeiro de 1999, a adoção de um novo regime monetário e cambial começou a mudar esse quadro, mas com muita lentidão, devido aos problemas acumulados no período anterior. Já no ano 2000, o crescimento do PIB acima de 4\%, a lenta recuperação das exportações e a rápida recuperação da agricultura contribuíram para a geração de empregos formais em volume razoável, reduzindo das taxas de desemprego. Porém, as crises externas de 2001 a 2003; tais como a quebra da Nasdaq, os escândalos financeiros nos EUA, o ataque às Torres Gêmeas e ao Pentágono, o calote da Argentina, o golpe na Venezuela, a guerra no Afeganistão, a guerra no Iraque e a escalada do preço das commodities impediram uma sólida recuperação do mercado de trabalho no Brasil, já que a estabilidade macroeconômica foi bastante abalada. Ainda segundo Prado (2006), o Estado brasileiro, ao assumir contornos de uma economia de mercado, se viu diante de um trade-off básico entre crescimento do emprego e uma seguridade social generosa, em que as contribuiçôes sociais, os impostos pesados, os salários altos e direitos trabalhistas amplos passaram a ser vistos como algo excessivamente custoso à classe patronal. 
A partir dos anos 90, o Estado brasileiro assume uma feição mais liberal no que se refere à desregulamentação do trabalho e do bem-estar e internaliza o processo de precarização nas relaçôes de trabalho em diversos setores, entre eles, o de saúde. Como assinala Polanyi (2000), nessa feição liberal o trabalho não deveria ser regulado, e passariam a ter validade as políticas que assegurassem a autorregulação pelo mercado, dando a este o único poder organizador na esfera econômica.

De acordo com essa brevíssima recuperação histórica, do ponto de vista do núcleo do sistema capitalista, os dilemas que se abrem, relativos à reorganização social da produção e do trabalho pós-década de 1990, agora devem ser entendidos não somente pelo rompimento de um padrão de relação entre capital e trabalho, mas também entre o Estado, que sai de sua posição histórica de mediador entre o capital e o trabalho - os três passam a operar numa economia governada por leis próprias num espaço social mundializado. Nesse novo desenho de relações, segundo Kuczinsky e Williamson (2004), a economia seria conduzida a um ambiente mais competitivo, de tal modo que o mercado se tornasse o principal determinante dos preços relativos e da alocação eficiente de recursos, reduzindo as ineficiências e aumentando a produtividade - por conseguinte, estimulando o crescimento e o emprego.

O objetivo deste artigo é argumentar, a partir da observação de um grupo de trabalhadores de uma cooperativa dentro de uma instituição pública de saúde, sobre os contextos políticos, econômicos e administrativos que levaram à adoção de relações precárias de trabalho; identificar a percepção desses profissionais acerca da precarização das suas relações de trabalho e descrever como esses profissionais percebem as consequências da precarização na sua saúde.

\section{Metodologia}

Trata-se de uma pesquisa descritiva, com abordagem quali-quantitativa, realizada junto a trabalhadores sob vínculos precários de relaçôes de trabalho, cuja modalidade de contratação é a cooperativa, dentro de uma unidade pública federal de saúde, no município do Rio de Janeiro. Esta unidade é considerada centro de referência para o estado e o município do Rio de Janeiro, nas áreas de saúde da mulher e do adolescente.

$\mathrm{O}$ instrumento de pesquisa qualitativa é constituído por um questionário, composto de duas perguntas e de preenchimento voluntário, cujo objetivo foi 
obter informações relativas à percepção desses trabalhadores sobre a precariedade de seu vínculo de trabalho e os impactos sobre sua saúde.

O critério de inclusão adotado foi o de trabalhar sob a modalidade de cooperativa e estar lotado no Serviço de Enfermagem.

Os dados relativos às variáveis idade, sexo, profissão e salário foram obtidos junto ao departamento pessoal da unidade estudada. A fim de facilitar a compreensão, estabelecemos quatro faixas salariais e etárias. As faixas salariais foram assim distribuídas: na primeira faixa estão os salários abaixo de $\mathrm{R} \$ 500,00$; na segunda, os salários entre $\mathrm{R} \$ 500,01$ e $\mathrm{R} \$ 1.000,00$; na terceira, os situados entre $\mathrm{R} \$ 1.000,01$ e $\mathrm{R} \$ 1.500,00$. Por fim, na última faixa estão os salários acima de $\mathrm{R} \$ 1.500,01$. Para as faixas etárias, na primeira estão as idades abaixo de 25 anos; na segunda, entre 26 e 35 anos; na terceira, entre 36 e 45 anos. Por último, as idades acima de 46 anos.

Esta pesquisa foi devidamente submetida ao Comitê de Ética em Pesquisa do Instituto de Estudos em Saúde Coletiva, da Universidade Federal do Rio de Janeiro, registrada, sob o $n^{\circ}$ de processo 30/2006 e parecer $n^{\circ}$ 69/2006, estando em conformidade com a Resolução CNS no 196/96.

\section{Resultados}

Fazem parte deste estudo os dados relativos aos trabalhadores cooperativados, lotados no Serviço de Enfermagem da unidade estudada. Optou-se pela pesquisa no Serviço de Enfermagem por este demandar o maior quantitativo de pessoal cooperativado da instituição. Dos 194 trabalhadores sob regime de cooperativa, 112 exerciam suas funções no referido serviço. É importante assinalar que apenas 18 trabalhadores preencheram o questionário. Este fato relaciona-se ao concurso público realizado pelo Governo Federal, a fim de reduzir os quadros de trabalhadores terceirizados por empresa e cooperativa. Vários desses profissionais não aprovados no referido concurso, diante da iminente demissão, argumentaram que não gostariam de participar da pesquisa. Portanto, não preencheram o questionário.

A unidade estudada, em 30 de julho de 2006, tinha sua força de trabalho assim distribuída: 659 servidores estatutários, 191 trabalhadores terceirizados por empresa e 194 trabalhadores terceirizados por cooperativa. Entretanto, interessanos o grupo de 112 trabalhadores terceirizados por cooperativa e lotados no Serviço 
de Enfermagem da instituição. Trata-se de um grupo cuja força de trabalho feminina, com 102 trabalhadoras (91,07\%), predomina em relação à masculina, cuja participação é de apenas 10 trabalhadores $(8,93 \%)$. Os 70 técnicos de enfermagem representam $62,5 \%$; seguidos de 31 enfermeiros, cujo percentual é de 27,68\%; os seis instrumentadores cirúrgicos e os cinco técnicos em radiologia, com representação de $9,82 \%$, finalizam a distribuição por profissão dentro do grupo. A distribuição salarial se dá em duas faixas, com 82 registros na faixa de $\mathrm{R} \$ 500,01$ a $\mathrm{R} \$ 1.000,00$, o que representa $73,21 \%$, e 30 registros na faixa de salários acima de $\mathrm{R} \$ 1500,01$, cuja representação é de $26,78 \%$. Na distribuição desses trabalhadores por faixas etárias, identificamos 45 na faixa dos 26 aos 35 anos de idade, o que representa 40,17\%; os 37 trabalhadores com idade até 25 anos representam 33,03\%, na faixa que vai dos 36 aos 45 anos, encontramos 23 trabalhadores, o que representa 20,53\%; para trabalhadores com idade acima 46 anos, registramos apenas sete, cuja representação é de $6,25 \%$.

A primeira pergunta do questionário desejou captar qual o entendimento dos trabalhadores acerca do trabalho precário e, das 18 respostas, dez mereceram destaque, pois as demais caracterizaram-se como repetições. As respostas apresentam-se transcritas da forma como foram respondidas no questionário:

1) “[...] o trabalho precário é ainda muito encontrado, apesar de tantas leis. As necessidades e falta de oportunidades nos faz aceitar, mesmo sabendo dos prejuízos e da insegurança [...]".

2) “[...] acho que o trabalho precário é um método muito inseguro e estressante, pois, nós cooperados não temos direitos do trabalhador, principalmente a longo prazo [...]".

3) "[...] é ruim, pois, trabalhar sem estar amparado pela lei ficamos à mercê da sorte, pois, ao adoecer não temos a quem recorrer $[\ldots]$ ".

4) “[...] não é o ideal, porém, quando não se encontra uma oportunidade com direitos recorremos a uma cooperativa, que nos emprega imediatamente [...]".

5) "[...] o profissional que se vincula ao trabalho precário, por falta de opção, tem consciência que pode ficar doente um dia, mas se afastar-se do trabalho, no fim do mês não tem salário.

6) Se um filho, mulher ou nossa mãe ficar doente, nem podemos pensar em tirar alguns dias para ficar em casa com o nosso ente querido [...]".

7) “[...] é uma falta de respeito, por que não temos nenhum valor [...]”.

8) “[...] esse vínculo só contribui para que os trabalhadores se acomodem, mesmo sabendo que a qualquer momento podem perder o trabalho e sair sem nada, desestruturado física e psicologicamente [...]”. 
9) “[...]não temos hora para sair e, em quase todos os plantões, só almoçamos às

14:00h ou 15:00h [...]”.

10) “[...] é horrível, pois dá uma sensação de insegurança e muito desconforto[...]".

A segunda pergunta tinha como objetivo entender como os trabalhadores associavam os danos à saúde com o trabalho precário. Das 18 respostas, oito mereceram destaque:

1) “[...] o trabalho precário, pelo medo, aumenta o estresse”.

2) "Traz uma sensação de inferioridade [...]".

3) “[...] percebo que a insegurança que vivo gera problemas fisiológicos e emocionais à minha saúde $[. .]$.$” .$

4) "[...] tenho enxaquecas, insônia, prisão de ventre e dor na coluna, com frequência e acho que é pelo nervoso [...]".

5) “[...] sinto-me diminuído em relação à equipe, a chefia e etc. [...]”.

6) "[...] tenho tendinite e dor na coluna, mas mesmo assim tenho que vir trabalhar todo dia $[\ldots] "$.

7) “[...] tenho muito cansaço e hipertensão, acho que é pela sobrecarga de trabalho $[\ldots] ”$.

8) “[...] não tenho estímulo para lutar [...]".

9) “[...] tenho taquicardia e obesidade, deve ser perda da autoestima [...]".

\section{Discussão}

Julgamos importante iniciar esta seção informando alguns problemas encontrados ao longo da pesquisa de campo. Os problemas têm origem no concurso público realizado pelo Governo Federal, a fim de reduzir os quadros de trabalhadores precários. Vários profissionais sob contrato de cooperativa fizeram o concurso e não conseguiram aprovação. Dentre vários argumentos, o mais enfatizado era o de que concorriam em desigualdade de condições com os demais. Muito desses profissionais já trabalhavam na instituição há quase uma década, não tinham tempo para estudar e estavam defasados nos conhecimentos específicos solicitados no concurso. Tendo em vista que o concurso foi realizado para substituir os trabalhadores cooperativados por servidores concursados, aqueles que não conseguissem aprovação seriam demitidos. Então, diante da iminência de perderem seus empregos, parte da revolta manifestava-se na negação ao 
preenchimento do questionário. Face ao exposto, somente 18 trabalhadores da cooperativa se dispuseram a preencher o questionário.

Com base nos autores Nogueira (2006), Antunes (2006), Pochmann (2004) e Esping-Andersen (1995), as características do trabalho em saúde e as formas de inserção desses profissionais no mercado de trabalho apontam para a urbanização, especialização, redução da remuneração, multiplicidade de vínculos empregatícios, participação crescente de mulheres na categoria, elevado número de plantões entre as formas de trabalho e crescente informalidade nas relaçôes de trabalho. Isso indica que o mercado de trabalho brasileiro no setor saúde vem reproduzindo a tendência geral da economia contemporânea, de utilizar o expediente da flexibilização da contratação da força de trabalho.

Na distribuição por faixa etária, notamos que as três primeiras faixas respondem por mais de $93 \%$ do total de trabalhadores. Consideramos relevante ressaltar que, nas duas primeiras faixas, que representam uma população jovem e altamente produtiva, temos 82 registros de trabalhadores. Portanto, como assinala Antunes (2006), essa reorganização social da produção, além de incorporar a mão de obra feminina, excluiu os trabalhadores mais velhos. Os jovens, ainda que com algum grau de qualificação, adentram ao mercado de trabalho à margem da legalidade. No setor saúde, isso se reflete diretamente na qualidade dos serviços ofertados à população demandatária.

Quando observamos a faixa salarial, etária e a composição do grupo de trabalhadores, além de jovens, são um grupo majoritariamente feminino. De acordo com Alves (2000), podemos estabelecer uma comparação entre o atual e o antigo modelo de reorganização social da produção e do trabalho. No modelo anteriormente construído, as relações entre o capital e o trabalho eram mediadas pelo Estado, que buscava soluções coletivas que se sobrepunham à estrita relação contratual privada de compra e venda da força de trabalho. No modelo de gestão, no qual o Estado reduziu os custos com a contratação de pessoal próprio na administração pública e subordinou a complexidade da prestação dos serviços públicos de saúde à lógica mercantil, explodiram as formas precárias de relaçôes de trabalho dentro das Instituiçôes do Estado.

Quanto à percepção desse trabalhador quanto a sua inserção informal e precária, notamos que ele conhece seus direitos e garantias sociais. Entretanto, entende que esses direitos são desrespeitados em função de uma conjuntura que 
o torna impotente de lutar. Essa conjuntura reorganiza o trabalho de tal maneira que o desvaloriza como ser humano. A falta de proteção social, a insegurança e o desrespeito às limitações físicas do seu corpo são consequências desse processo. $\mathrm{O}$ medo de perder o emprego e as doenças que sobre ele advêm constituem em reações desse ser a essa conjuntura que o subordina. Alves (2000) assinala que esse processo de precarização das relações de trabalho é uma forma de legitimação de relações de poder da classe empregadora sobre a trabalhadora, que se insere num contexto histórico de respostas do modo de produção capitalista a um modelo anterior, de base capitalista, mas que garantia alguns direitos aos trabalhadores. Portanto, a relação precária de trabalho é algo que dificulta a capacidade de organização da classe trabalhadora e legitima, pela via da fragmentação, o poder do capital sobre o trabalho.

É importante ressaltar a preocupação desse trabalhador quando se refere a sua possível condição social e material no longo prazo. Ou seja, hoje ele tem forças para trabalhar, ainda que sem garantias sociais. Mas, em breve, não mais será útil a esse modelo de exploração da sua força de trabalho. Segundo Abramides e Cabral (2003), sintomas como insônia, obesidade, medo, insegurança e sensação de inferioridade, embora subjetivos, são sintomas de saúde que apontam para uma relação de trabalho precária, pois quando predominavam as relações de trabalho de natureza formal, outros sintomas relacionavam a doença ao trabalho desenvolvido. Hoje, face à precariedade das relações de trabalho, as doenças assumiram formas mais subjetivas, tornando difícil associá-las à atividade laboral. Por exemplo; não é possível afirmar que insônia, obesidade, medo e insegurança são sintomas de trabalhadores precários. No entanto, podemos inferir que novas doenças ocupacionais acometem os trabalhadores e têm como uma das causas o trabalho inseguro e precário.

Assinala Alves (2000) que o processo de precarização do trabalho leva o trabalhador à adoção de rotinas extras, a fim de garantir seu sustento e de sua família. De acordo com o autor, podemos inferir que a tendinite e dor na coluna refletem o desrespeito às limitações físicas do corpo causado pelas rotinas de trabalhos extras, a fim de complementar a renda obtida no trabalho da cooperativa.

A convivência entre dois grupos de trabalhadores no mesmo local, dividindo-se entre estatutários e cooperativados, agudiza a sensação de inferioridade em relação à equipe de trabalho, conforme destacado nas respostas. Para Antunes (2006), 
o modelo de precarização necessita de um pequeno grupo de trabalhadores qualificados e seguros para as funções de comando e um outro grupo, maior, de trabalhadores para dar funcionalidade ao sistema. Na unidade estudada, esse grupo maior é composto pelos cooperativados, cuja relação de trabalho é precária.

Como vimos nas respostas dos trabalhadores, há consciência do nível de exploração. No entanto, essa forma de apropriação da força de trabalho impõe, involuntariamente, ao trabalhador, sua adesão ao projeto neoliberal de gestão da força de trabalho, em que a desmontagem dos direitos sociais dos trabalhadores, o combate ao sindicalismo classista e estímulo ao sindicalismo de resultados são traços marcantes desse projeto.

\section{Considerações finais}

Segundo Antunes (2006), o modelo de Estado mediador que deu sustentação ao Estado de Bem-Estar Social vem sendo substituído por ações antissociais que caracterizam o modelo neoliberal de gestão do Estado. As relações de trabalho que caracterizaram o padrão fordista de produção também vêm sendo substituídas por formas flexibilizadas e desregulamentadas, alterando as relações de compra e venda da força de trabalho, levando à perda dos direitos sociais e à degradação das condiçôes de vida de enormes contingentes de homens e mulheres que têm no trabalho o seu sustento.

Como observa Girardi (1999), no setor de saúde esse processo afeta duplamente a sociedade. Por um lado, compromete a qualidade da assistência prestada aos demandatários dos serviços públicos de saúde; por outro, desprotege das garantias sociais mínimas aqueles que prestam os serviços à sociedade. Isto embute uma enorme contradição dentro do próprio modelo de gestão adotado; os programas e políticas governamentais para o setor saúde podem sofrer descontinuidade por se apoiarem em trabalhadores cuja relação laboral é extremamente instável e por não conseguir, através da remuneração livre da força de trabalho, nos moldes liberais do século XIX, substituir as garantias sociais pela econômica.

Observamos que os trabalhadores têm consciência da sua relação precária e das implicações do seu vínculo na assistência aos demandatários dos serviços de saúde, bem como nas consequências desse vínculo em relação a sua satisfação profissional. 
No que depender do trabalhador, dada a percepção acerca da natureza de seu vínculo de trabalho, ele conhece a dimensão do problema, bem como da exploração da sua força de trabalho. Ele também percebe que alguns sintomas de seu estado de saúde podem ter nexo causal com o seu vínculo de trabalho, que desrespeita os limites do seu corpo. Portanto, submete-se a esse tipo de vínculo consciente de que é algo maior que sobre ele se impõe, não lhe restando nenhuma opção.

Segundo Nogueira (2006), o setor saúde, que se caracterizava como atividade "artesanal", individualizada e autônoma, transformou-se progressivamente, nos moldes do modo de produção capitalista, numa empresa. Hoje é entendido como um segmento do setor de serviços da atividade econômica, cujos trabalhadores foram submetidos às regras impostas aos demais trabalhadores de qualquer empresa, tais como instabilidade no emprego, flexibilização, ritmo intenso de trabalho e jornadas de trabalho prolongadas. Tudo isso somado às históricas particularidades do trabalho em saúde, como aliviar a dor e o sofrimento, e ter a morte como situação rotineira.

Entendemos que o processo neoliberal tem avançado e, independentemente de setores da atividade econômica, subordina toda a lógica social com seus desdobramentos e complexidade, à lógica mercantil. No setor público de saúde não tem sido diferente. $\mathrm{O}$ contexto econômico, sob a doutrina neoliberal, impõe a restrição de gastos públicos, inclusive para contratação de pessoal. Por um lado, a extinção de quadros de carreiras dentro do funcionalismo público serviu para acelerar o processo de não-modernização da estrutura de carreiras e terceirização de uma série de atividades laborais. Por outro, a demanda pelos serviços públicos de saúde sofreu incremento constante, face à perda do poder aquisitivo da população. Estando o governo amarrado ao modelo adotado, não pode responder com aporte de pessoal às unidades públicas de saúde. Estas adotaram formas precárias de relações de trabalho, como a terceirização por cooperativas, a fim de responder à demanda da sociedade pelo serviço público de saúde.

Nesse sentido, segundo Antunes (2006), as mudanças nas formas de organização social do trabalho constituem estratégias pelas quais o modo de produção capitalista busca superar a crise do seu padrão de acumulação que prevaleceu, em especial no período Pós-Segunda Guerra Mundial, durante o qual, diferentemente do que se observa nos dias atuais, a organização social 
da produção permitia uma articulação com os movimentos dos trabalhadores, fortalecendo-os como categoria.

Os elementos que apresentamos nos permitem identificar uma enorme contradição na nova organização social do trabalho. Por um lado, há um apelo no sentido de qualificação dos trabalhadores, diante dos avanços tecnológicos que foram incorporados ao setor de serviços, dentre eles o de saúde. Por outro, em sentido radicalmente inverso, uma desqualificação presente no trabalho precário, informal e temporário que, a nosso ver, está plenamente em sintonia com a lógica neoliberal de gestão do trabalho.

Então, de acordo com Antunes (2006), há alguns elementos que explicam essa contradição. Com a grande expansão da doutrina neoliberal, a partir de fins da década de 70 e a consequente crise do Estado de Bem-Estar Social, deu-se um processo de regressão dos movimentos sindicais, que passaram a atuar sob uma lógica de resultados. A doutrina neoliberal passou a ditar o programa a ser implementado pelos países de economias capitalistas, inicialmente os centrais e logo depois os da periferia do sistema. Essa doutrina, dentre outras coisas, contemplava a reestruturação das atividades produtivas, privatização acelerada, enxugamento do Estado, políticas fiscais e monetárias definidas por organismos mundiais, como Fundo Monetário Internacional e Banco Mundial. Então, a precarização do trabalho é parte de um processo complexo que pode ser resumido em dois grandes eixos de reflexão. O primeiro deles era a desmontagem do Estado de Bem-Estar Social. O segundo, a implementação de um projeto econômico, social e político que atingisse o mundo do trabalho, reorganizando as relações de compra e venda da força de trabalho pelas leis de mercado.

Portanto, numa economia mundializada, a importância do Estado na proteção dos indivíduos e de seu reconhecimento sócio-profissional deve aumentar. $\mathrm{O}$ emprego deve ser entendido como uma variável-chave para o desenvolvimento e o Estado deve ter postura pró-ativa na geração de postos de trabalho, pois os 20 anos de neoliberalismo fizeram o Brasil saltar de um desemprego aberto apenas friccional (em torno de 3\%) para 7\%, na década de 80, e dois dígitos (15\%) nos anos 90 (POCHMANN, 2004). Por isso, a precarização do trabalho constitui-se num problema de Estado e não somente de reorganização econômica da produção. 
ABRAMIDES, Maria; CABRAL, Reis. Regime de acumulação flexível e saúde do trabalhador. São Paulo em Perspectiva. São Paulo, v. 17, n. 1, p. 3-10, jan-mar 2003.

ALVES, Giovanni: O novo (e precário) mundo do trabalho. São Paulo: Boitempo, 2000.

ANTUNES, Ricardo. Adeus ao trabalho: ensaios sobre as metamorfoses e a centralidade do mundo do trabalho. São Paulo: Cortez, 2006.

ESPING-ANDERSEN, Gosta. As três economias políticas do Welfare State. Princeton, NJ: Princeton University Press, 1995.

GIRARDI, Sábado. A regulação dos recursos humanos em saúde e a reforma do setor saúde em países da América Latina. Brasília: OPAS/OMS, 1999.

JUNIOR, Caio. Formação do Brasil contemporâneo. São Paulo: Brasiliense, 1999.

KUCZINSKY, Pedro; WILLIAMSON, John. Depois do Consenso de Washington. retomando o crescimento e a reforma na América Latina. São Paulo: Saraiva, 2004.

MORETTI, Bruno: A questão do trabalho na experiência periférica. Oikos, Revista de Economia Heterodoxa, ano V, n. 6, p. 88-101, 2006.

NOGUEIRA, Roberto. Problemas da gestão de recursos humanos no Ministério da Saúde. Brasília: ObservaRH/NESP/CEAM/UnB, 2006.

POCHMANN, Márcio. Efeitos da internacionalização do capital no mundo do trabalho. São Paulo em Perspectiva, São Paulo, v. 18, n. 2, p. 3-16, abr-jun 2004.

POLANYI, Karl. A grande transformação. São Paulo: Campus, 2000.

PRADO, Antônio. A revitalização do mercado de trabalho brasileiro. Visão do Desenvolvimento, BNDES, n. 22, p. 1-8, dez 2006.

STANDING, Guy. Structural adjustment and labour market policies. In: STANDING, Guy; TOKMAN, Victor (Ed.). Towards social adjustment: labour market issues in structural adjustment. Geneva: International Labour Office, 1991.

TAVARES, Conceição. Ajuste e reestruturação nos países centrais: a modernização conservadora. In: . (Des)Ajuste global e modernização conservadora. São Paulo: Paz e Terra, 1993. p. 97-142.

TEIXEIRA, Aluísio. "O império contra-ataca”: notas sobre os fundamentos da atual dominação norte-americana. Economia e Sociedade, Campinas, n. 15, p. 1-13, 2000. 


\section{The invisibility of the hidden ones}

This paper discusses the symptoms of the precariousness of work as a new and complex social issue. We seek to describe the human dimensions involved in the work process, reflecting the level of exploitation of their poor relations. Among the results, we highlight the relationship that these workers made of their health symptoms with their work link work. The precarious work relation associated with low incomes may bring physical manifestations of insomnia and fear, reflecting the loss of self-esteem. We discussed the current social reorganization of production due to the crisis and restructuring of capitalism in the last quarter of the 20th century, which affected the world of work, scrambling relations that have shaped the state of Social Welfare and rearranging them under the market regulation. We conclude that the employee, in face of his precarious work relationship, is mainly concerned with the lack of social guarantees, and its consequences in the long run, when he will be no more useful for this type of workforce exploitation. The research was conducted with 112 workers contracted by a cooperative, in a Nursing Service of a public health center of the Health Ministry, located in Rio de Janeiro city.

> Key words: workers' health; precarious work relations; neoliberalism; Welfare State. 